* O correto é ficar na seguinte ordem: Mestre e Doutoranda em direito de empresa e atividades econômicas pela Universidade do Estado do Rio de Janeiro (UERJ). Especialista em Direito Civil Constitucional pela Universidade do Estado do Rio de Janeiro (UERJ). Graduada em Direito pela Universidade Federal do Rio de Janeiro (UFRJ). Advogada. Email: leticialalisboa@yahoo.com. br

** Doutor em Ciências pela Escola Nacional de Saúde Pública Sérgio Arouca (ENSP) da Fundação Oswaldo Cruz (FIOCRUZ). Professor Adjunto de Direito Comercial da Faculdade de Direito da Universidade do Estado do Rio de Janeiro (UERJ).

Email:1santanna44@gmail. com

\section{Dissolução Das Sociedades à luz das Alterações Previstas no Código de Processo Civil de 2015}

DISSOLUTION OF COMPANIES IN LIGHT OF THE CHANGES BROUGHT ON BY THE BRAZILIAN CODE OF CIVIL PROCEDURE OF 2015

\section{Leticia Lobato Anicet Lisboa* Leonardo da Silva Sant'Anna***}

Como citar: LISBOA, Letícia Lobato Anicet, SANT’ANNA, Leonardo da Silva. Dissolução das sociedades à luz das alterações previstas no Código de Processo Civil de 2015. Scientia Iuris, Londrina, v. 21, n. 3, p.158-188, nov. 2017. DOI: $10.5433 / 2178-8189.2017 \mathrm{v} 21 \mathrm{n}$ 3p158. ISSN: $2178-8189$.

Resumo: O presente artigo tem como objetivo apresentar as alterações promovidas pela Lei $\mathrm{n}^{0} 13.105$, de 16 de março de 2015 no que tange à dissolução de sociedades. Desta forma, inicialmente serão apontadas as causas de dissolução de sociedades à luz do Código Civil de 2002. Por conseguinte, serão analisados os aspectos processuais de dissolução de sociedades estabelecidos pelo Código de Processo Civil de 1973 e Código de Processo Civil de 1939, ambos revogados pelo novo diploma processual. Ao final, serão observados os novos procedimentos 
processuais da dissolução de sociedades, à luz do Código de Processo Civil de 2015, especialmente o procedimento de dissolução parcial de sociedades, ali regulamentado. O método utilizado para o trabalho foi dedutivo, a pesquisa realizada foi de caráter documental e envolveu a análise de legislação, além de estudos doutrinários, jurisprudenciais e exame de artigos em periódicos.

Palavras-Chave: Dissolução. Código de processo civil. Direito societário. Direito processual.

Abstract: The purpose of this paper is to present the changes introduced by Law $\mathrm{n}$. 13,105 (Brazilian Code of Civil Procedure), of March 16th, 2015, specifically in regards to the dissolution of companies. Originally, the causes of dissolution can be found in the Brazilian Civil Code of 2002. In spite of that, this study analyzes the procedural aspects of a company's dissolution previously established by the Civil Procedure Code of 1973 and Civil Procedure Code of 1939 - both repealed by the 2015 procedural code. In summary, this new law has various requirements, which has to be observed, even in the case of a company's partial dissolution. This research utilized the deductive method and literature review, with the use of legislation, books, case studies and other research papers.

Keywords: Dissolution. Civil procedure code. Corporate law. Procedural law. 


\section{INTRODUÇÃO}

A dissolução de sociedades trata-se da fase de desconstrução do vínculo societário, com a retirada, falecimento ou exclusão de um ou mais sócios, no caso de uma dissolução parcial, ou ainda com a extinção da sociedade e da sua personalidade jurídica, nas hipóteses de dissolução total.

Deste modo, a dissolução total de sociedades foi positivada pelo Código Comercial de 1850, e pelos diplomas posteriores, sendo certo que sua formalização se dá por causas de pleno direito ou judiciais, quando há a necessidade de decretação judicial da dissolução total.

Por outro lado, a dissolução parcial foi objeto de construção pretoriana e doutrinária, com base nos princípios de preservação da empresa e função social, levando-se em consideração que a vontade de um ou mais sócios, não deve prevalecer sobre os interesses metaindividuais da sociedade em geral, ou seja, consumidores, fornecedores, funcionários, entre outros.

O Código Civil de 2002 instituiu a resolução da sociedade em relação a um sócio, nas hipóteses de morte do sócio, exercício de direito de retirada e exclusão pelos demais sócios, sendo necessária a apuração de haveres para liquidação da respectiva quota-parte.

Sob esta ótica, a Lei n ${ }^{\circ} 5.869$, de 11 de janeiro de 1973 (Código de Processo Civil de 1973) determinou, através da manutenção do Decreto-lei n ${ }^{\circ} 1.608$, de 18 de setembro de 1939 (Código de Processo Civil de 1939), os procedimentos especiais da dissolução total e liquidação da sociedade.

Contudo, a referida legislação foi revogada pelo novo Código de Processo Civil (Lei no 13.105, de 16 de março de 2015) que passou a 
vigorar a partir de 16 de março de 2016, e instituiu a Ação de Dissolução Parcial de Sociedades como procedimento especial, conforme será visto adiante.

O primeiro capítulo tem como objetivo específico apresentar causas que geram a dissolução de sociedades previstas no Código Civil, analisando os conceitos de dissolução total e parcial.

Por conseguinte, o segundo capítulo apresentará os procedimentos para dissolução total e parcial previstos na Lei $\mathrm{n}^{0} 5.869$, de 11 de janeiro de 1973 (Código de Processo Civil de 1973), com foco no procedimento especial de dissolução total previsto no Decreto-Lei ${ }^{0} 1.608$, de 18 de setembro de 1939 (Código de Processo Civil de 1939).

O terceiro capítulo, por fim abordará os novos procedimentos para dissolução das sociedades, previstos no Código de Processo Civil de 2015, especialmente com relação ao procedimento especial da ação de dissolução parcial de sociedades, novidade introduzida pelo diploma processual.

\section{OS FUNDAMENTOS ACERCA DA DISSOLUÇÃO DAS SOCIEDADES CONFORME AS DISPOSIÇÕES DO CÓDIGO CIVIL DE 2002}

A dissolução parcial de sociedades a é resolução da Sociedade em relação a um ou mais sócios, levando a liquidação da sua quotaparte no capital social. Sérgio Campinho (CAMPINHO, 2014, p. 124) se utilizando da nomenclatura expressa no Código Civil de 2002, trata da dissolução parcial como a resolução da sociedade em relação a um sócio, conforme este informa:

O Código Civil, incorporando conceito já assente 
na doutrina e consagrado na jurisprudência, prevê, de forma expressa, a figura da dissolução parcial da sociedade, nas hipóteses de retirada, exclusão ou morte do sócio.

Esta disciplina é feita sob a nomenclatura "da resolução da sociedade em relação a um sócio".

[...] Preferiu o Código fazer o uso desta nova expressão, em substituição à clássica dissolução parcial da sociedade. Quando aborda o tema dissolução, o faz sob a ótica da dissolução total da sociedade, como se deduz da Seção IV, do Capítulo I, do Subtítulo II, do Título II, do Livro II.

Na vigência do Código Comercial de 1850 e do Código Civil de 1916, prevalecia a teoria contratualista, que privilegiava a vontade dos sócios sobre o interesse institucional, existindo tão apenas a modalidade de dissolução total, de pleno direito ou judicial conforme elucida Rubens Requião (REQUIÃO, 2012, p. 410):

O Código Comercial regulou a dissolução das sociedades comerciais sob o império da doutrina individualista que dominava o pensamento jurídico no século XIX. O instituto da dissolução da sociedade tinha por precípua finalidade proporcionar a libertação do sócio de seus compromissos sociais. Esse era o supremo princípio que ditou a elaboração da Seção VIII do Título XV do antigo diploma imperial, inspirada no Code de Commerce de 1807, que se transpôs para o nosso, facilitando a dissolução da sociedade em hipóteses que atualmente o direito somente conceberia para a despedida ou exclusão de sócio. Naquele sistema predominante, duas formas de dissolução existiam: a dissolução de 
pleno direito e a dissolução judicial. Catalogou o art. 335 a primeira forma, ao declarar que se reputam dissolvidas as sociedades: "1) expirando o prazo ajustado da sua duração; 2) por quebra da sociedade, ou de qualquer dos sócios; 3 ) por mútuo consenso de todos os sócios; 4) pela morte de um dos sócios, salvo convenção em contrário a respeito dos que sobreviverem; 5) por vontade de um dos sócios, sendo a sociedade celebrada por tempo indeterminado". Assim, ocorrendo um desses eventos pretendia o Código que estivesse dissolvida de pleno direito a sociedade, que continuaria somente para se ultimarem as negociações pendentes, procedendo-se à liquidação das ultimadas.

Neste sentido, foi ganhando espaço os princípios da preservação e da função social da empresa, logo, os Tribunais passam a entender que alguns sócios não podem impor sua vontade em dissolver a sociedade, sobre a vontade dos demais.

A jurisprudência e doutrina ${ }^{1}$ então passaram a adotar o instituto

1 Cf. a seguinte Ementa: Ação de dissolução de sociedade cumulada com apuração de haveres. Sociedade limitada. Procedimento bifásico. Artigo 1.218, VII, do CPC. Primeira fase que garante ao sócio dissidente o exercício do seu direito potestativo de recesso. Incidência dos artigos 1.029, 1.031 a 1.033 do CC. Sociedade familiar constituída entre pai e filha. Alegação da autora de que após ter conhecimento da má administração realizada por seu genitor, buscou auxiliá-lo, mas, no entanto, não conseguiu participar das decisões sociais. Em defesa, os réus afirmam que a dissolução trará prejuízos à sociedade, destacando que a situação financeira da pessoa jurídica foi prejudicada pela própria demandante que adquiriu dois veículos para uso pessoal, em nome da sociedade, cujo contrato foi anulado por sentença transitada em julgado. Pedido inicial fundamentado na quebra da affectio societatis. Aferição de culpa que é desinfluente para o resultado da demanda. Falta de razoabilidade no alegado cerceamento de defesa, uma vez que ninguém é obrigado a manter-se vinculado, sem que subsista tal ânimo. Sociedade limitada constituída intuito personae. Pedido de dissolução da sociedade acolhido pela sentença. Razões de apelação confusas, mas que deixam entrever o desejo do sócio remanescente de continuar com a atividade empresarial desenvolvida. Princípios da função social dos contratos e da preservação da empresa. Benefícios coletivos que transcendem à vontade dos sócios. Direito da sócia minoritária resguardado na medida em que lhe é garantida sua retirada, com a consequente apuração de seus haveres. Conturbada e lamentável relação entre os sócios. Eventual prejuízo da pessoa jurídica, que não impede a liquidação da cota-parte a que tem direito a autora. Recurso a que se dá parcial provimento (BRASIL, 2012). 
da dissolução parcial no intuito de preservar a atividade econômica, tendo como exemplo a decisão abaixo, do Tribunal de Justiça do Rio de Janeiro que determinou a manutenção da sociedade, pela vontade do sócio remanescente, em razão da função social dos contratos e preservação da empresa, até que a resolução da sociedade em relação a um sócio foi tipificada pela edição da Lei no 10.406 , de 10 de janeiro de 2002.

A dissolução parcial tem fundamento no princípio da preservação da empresa e função social, e visa evitar a dissolução total e liquidação quando há quebra da affectio societatis. Cumpre salientar, que parte da doutrina ${ }^{2}$ era contrária à nomenclatura dissolução parcial, considerando que o Código Civil de 2002, trata na Seção V, do Capítulo I, do Subtítulo II, do Título II, do Livro II, expressamente da "Resolução da Sociedade em Relação a um Sócio".

Deste modo, o princípio da preservação da empresa reconhece que em torno do funcionamento regular e desenvolvimento de cada empresa, não gravitam apenas os interesses individuais dos empresários e empreendedores, mas também os metaindividuais de trabalhadores, consumidores e outras pessoas; são estes últimos interesses que devem ser considerados e protegidos, na aplicação de qualquer norma de direito comercial.

As hipóteses de dissolução parcial de sociedade, contemplam: (i) morte do sócio; (ii) direito de retirada; e (iii) a exclusão do sócio.

A morte do sócio está prevista no art. 1.028 do Código Civil, e determina que nesta hipótese a quota será liquidada, como será visto posteriormente.

Este dispositivo apenas será aplicado à sociedade limitada se o

2 Conforme Rubens Requião, o Prof. Hernani Estrella, não se conformava com essa linguagem. Porém o uso tornou a denominação corrente, especialmente nas decisões judiciais e na doutrina (ESTRELLA, 1948 apud REQUIÃO, 2012, p. 320). 
contrato social for omisso e não prever a cláusula de regência supletiva pela Lei das S.A.

Além disso, não ocorrerá a liquidação da quota, quando os demais sócios optarem por dissolver a sociedade totalmente, e no caso de substituição do sócio falecido pelos herdeiros, conforme art. 1.0283 do Código Civil (BRASIL, 2002).

O Direito de Retirada do sócio, previsto no art. 1.0294 do Código Civil, significa sua saída voluntária. Portanto, trata-se de um direito potestativo do sócio. É o direito potestativo do sócio de se retirar da sociedade. A sociedade deve, portanto, proceder à liquidação da quota, não podendo se recusar à retirada, considerando que a retirada é uma saída voluntária do sócio. Dele é a iniciativa de se retirar da sociedade.

O sócio, conforme art. 1.029 do Código Civil, poderá se retirar da sociedade, quando de prazo indeterminado, mediante a notificação aos demais sócios, com antecedência mínima de 60 (sessenta) dias. Caso o contrato social seja de prazo determinado, o sócio para exercer seu direito de retirada, deverá provar judicialmente justa causa.

Não obstante as determinações do art. 1.029 do Código Civil, este deve ser analisado em conjunto com a norma prevista do Art. 1.077 do Código Civil ${ }^{5}$ que determina que quando ocorrer fusão, incorporação ou modificação do contrato social, o sócio que dissentiu possuirá o direito

3 Art. 1.028. No caso de morte de sócio, liquidar-se-á sua quota, salvo: I - se o contrato dispuser diferentemente; II - se os sócios remanescentes optarem pela dissolução da sociedade; III - se, por acordo com os herdeiros, regular-se a substituição do sócio falecido. (BRASIL, 2002).

4 Art. 1.029. Além dos casos previstos na lei ou no contrato, qualquer sócio pode retirar-se da sociedade; se de prazo indeterminado, mediante notificação aos demais sócios, com antecedência mínima de sessenta dias; se de prazo determinado, provando judicialmente justa causa.

Parágrafo único. Nos trinta dias subseqüentes à notificação, podem os demais sócios optar pela dissolução da sociedade. (BRASIL, 2002).

5 Art. 1.077. Quando houver modificação do contrato, fusão da sociedade, incorporação de outra, ou dela por outra, terá o sócio que dissentiu o direito de retirar-se da sociedade, nos trinta dias subseqüentes à reunião, aplicando-se, no silêncio do contrato social antes vigente, o disposto no art. 1.031. (BRASIL, 2002). 
de retirar-se da sociedade no período de 30 (trinta) dias após a reunião, quando será realizada a liquidação da quota, conforme procedimento descrito nos próximos capítulos.

Deste modo, o direito de retirada do sócio, embora seja um direito potestativo, não pode ser manifestado a qualquer tempo, conforme a vontade do sócio. De acordo com o art. 1.077, ele tem um prazo de 30 (trinta) dias para exercer esse direito, nas hipóteses de alteração societária. Em quaisquer outros casos, pelo art. 1.029, ele tem um prazo de 60 (sessenta) dias, caso o contrato social seja de prazo indeterminado.

Caso seja negado o direito de retirada ou se forem estabelecidas condições sem amparo na lei para que este se retire, o sócio deve ingressar em juízo com uma ação pedindo que o juiz reconheça seu direito de retirada e que proceda à liquidação da quota.

A exclusão do sócio, trata-se de uma saída compulsória do sócio. Os demais sócios deliberam pela exclusão do mesmo. O art. $1.085^{6}$ do Código Civil, constante do capítulo de sociedades limitadas, trata da exclusão do sócio pela forma extrajudicial, mas faz expressa remissão ao art. $1.030^{7}$, ou seja, da forma judicial, razão pela qual devem ser vistos como complementares.

Neste sentido, a exclusão extrajudicial do sócio está prevista no art. 1.085, e pressupõe que ocorrerá sempre em relação a sócios minoritários. Ou seja, não se admite a aplicação do art. 1.085 para excluir

6 Art. 1.085. Ressalvado o disposto no art. 1.030, quando a maioria dos sócios, representativa de mais da metade do capital social, entender que um ou mais sócios estão pondo em risco a continuidade da empresa, em virtude de atos de inegável gravidade, poderá excluí-los da sociedade, mediante alteração do contrato social, desde que prevista neste a exclusão por justa causa.

Parágrafo único. A exclusão somente poderá ser determinada em reunião ou assembleia especialmente convocada para esse fim, ciente o acusado em tempo hábil para permitir seu comparecimento e o exercício do direito de defesa. (BRASIL, 2002).

7 Art. 1.030. Ressalvado o disposto no art. 1.004 e seu parágrafo único (exclusão de sócio remisso), pode o sócio ser excluído judicialmente, mediante iniciativa da maioria dos demais sócios, por falta grave no cumprimento de suas obrigações, ou, ainda, por incapacidade superveniente. (BRASIL, 2002). 
sócio majoritário.

A exclusão do sócio deve ser deliberada em reunião ou assembleia. Nos termos do parágrafo único do art. 1.085, a reunião ou assembleia tem que ser específica, isto é, realizada apenas para deliberar a exclusão do sócio, tendo sido este convocado, em tempo hábil, para participar e exercer o direito de contraditório. A decisão deve ser tomada pela maioria dos sócios, representativa de mais da metade do capital social.

O ato deve ser motivado, contudo, a lei é subjetiva e estabelece que apenas o sócio poderá ser excluído, quando os demais entenderem que este realizou "atos de inegável gravidade que estão pondo em risco a continuidade da empresa". Entretanto, o contrato social deve expressamente prever a exclusão do sócio por justa causa.

A falta de qualquer desses requisitos, previstos no parágrafo único e caput do art. 1.085, pode ensejar a anulação da deliberação. Deliberada a exclusão, deve-se promover a alteração contratual e proceder à liquidação da quota do sócio excluído (art. 1.086 c/c art. 1.031). Justamente por isso não se permite que o sócio majoritário seja excluído, pois a sociedade não teria como arcar com a liquidação da quota.

Conforme visto anteriormente, o art. 1.085 cita como exceção, a exclusão judicial de sócio, mediante iniciativa da maioria, que pode ocorrer nas hipóteses de falta grave no cumprimento das obrigações; e incapacidade superveniente. Embora a lei admita a continuidade da empresa pelo sócio incapaz, que a exercia enquanto capaz, na forma do caput do art. $974^{8}$ do Código Civil, os demais sócios podem não querer que o incapaz continue na sociedade, devendo nesta hipótese ajuizar ação

8 Art. 974. Poderá o incapaz, por meio de representante ou devidamente assistido, continuar a empresa antes exercida por ele enquanto capaz, por seus pais ou pelo autor de herança. (BRASIL, 2002). 
de dissolução parcial. Contudo, há uma divisão doutrinária sobre o critério para contabilizar a maioria dos sócios para exclusão judicial do sócio.

Por uma primeira interpretação, o critério utilizado para contabilizar a iniciativa é o por cabeça - per capita - segundo o qual cada sócio equivale a um voto. Portanto, os sócios minoritários poderiam excluir o sócio majoritário.

Conforme a segunda interpretação, a maioria dos demais sócios deve ser entendida como maioria do capital social, no sentido do art. $1010, \S 1^{\circ}$, do CC, pelo que os sócios minoritários não poderiam excluir o sócio majoritário.

Por outro lado, a Dissolução Total ocorre quando a sociedade se resolve como um todo encerrando a consecução de seu objeto e abrindo caminho para sua liquidação, conforme elucida Sérgio Campinho (CAMPINHO, 2014, p. 132):

A dissolução da sociedade consiste na verificação de uma causa que desencadeará o processo de extinção da pessoa jurídica, adquirida a partir do registro de seu ato constitutivo. Verificada a causa dissolutória, engrena-se a liquidação do ativo da sociedade para o consequente pagamento do passivo social, procedendo-se, em sequência, à partilha do acervo remanescente entre os sócios. Ultimada a fase de liquidação com a partilha, a sociedade estará extinta.

As hipóteses de dissolução total são caracterizadas como de pleno direito, cujas causas geram automaticamente a dissolução da sociedade, independentemente de decretação judicial, ou judiciais, que importam na obrigatoriedade de ajuizamento de ações, para promoção da dissolução total. Estas hipóteses de estão previstas no art. 1.033 
do Código Civil, sem prejuízo de outras previstas no Contrato Social, conforme enuncia o art. 1.035'. Da mesma forma, a Lei de Sociedade por Ações (Lei n ${ }^{\circ}$ 6.404/76), traz as hipóteses de dissolução de pleno direito em espelhamento aos arts. 1.033 e 1.035 do Código Civil.

Importante recordar que as sociedades contratuais também serão dissolvidas totalmente quando for a vontade dos sócios remanescentes no caso de morte ou retirada de um ou mais sócios nos termos do art. 1.028, II e 1.029, parágrafo único do Código Civil.

O art. 1.033 do Código Civil prevê nos seus incisos as seguintes hipóteses de dissolução total de pleno direto: (i) vencimento do prazo de duração da sociedade; (ii) consenso unânime dos sócios; (iii) deliberação dos sócios, por maioria absoluta; (iv) falta de pluralidade dos sócios, não reconstituída no prazo de 180 (cento e oitenta) dias; e (v) extinção de autorização para funcionar.

O vencimento do prazo de duração da sociedade importará em dissolução total de pleno direito, exceto se após o vencimento a sociedade não entrar em liquidação, caso em que se prorrogará por tempo indeterminado. Trata-se de dissolução de pleno direito, pois independe de decretação judicial, e independe de novo ato pelos sócios.

No regime anterior não se previa a prorrogação do contrato após o vencimento do prazo (art. 35, IV, Lei 8934/94) ${ }^{10}$. Com o advento do Código Civil de 2002 a ausência de oposição e a continuação da atividade social implicam automaticamente a prorrogação do contrato social por prazo indeterminado. (Art. 1.033, I do Código Civil).

A segunda e terceiras hipóteses de dissolução total de pleno

9 Art. 1.035. O contrato pode prever outras causas de dissolução, a serem verificadas judicialmente quando contestadas. (BRASIL, 2002).

10 Art. 1.399. Dissolve-se sociedade: I- Pelo implemento da condição, a que foi subordinada a sua durabilidade, ou pelo vencimento do prazo estabelecido no contrato. [...] (BRASIL, 2002).

SCIENTIA IURIS, Londrina, v.21, n.3, p.158-188, nov.2017 DOI: $110.5433 / 2178-8189.2017 \mathrm{v} 21 \mathrm{n} 3$ p158 
direito da sociedade, podem ser resumidas como dissolução total por vontade dos sócios, que abrangem o consenso unânime dos sócios e deliberação dos sócios por maioria absoluta. Esta circunstância independe de ser a sociedade por prazo determinado e indeterminado.

Em caso de Sociedade Limitada a dissolução por deliberação depende de aprovação de $3 / 4$ (três quartos) do capital social, conforme disciplinam os arts. 1.071, IV, e 1.076, I do Código Civil. Quando houver o consentimento de todos para resolver a sociedade, liquidar o patrimônio comum e extinguir a pessoa jurídica, essa dissolução pode ser efetivada antes do prazo determinado para o fim da sociedade.

Contudo,no caso de sociedade de prazo indeterminado, a maioria absoluta poderá deliberar para a extinção da pessoa jurídica.

Fabio Ulhôa Coelho (2012a, p. 351), afirma ainda que a jurisprudência tem reconhecido, à luz do princípio da preservação da empresa, que um único sócio, ainda que minoritário, tem o direito de continuar a sociedade - admitindo nela pelo menos mais um outro sócio.

A jurisprudência, contudo, é assente no sentido de que, havendo oposição de um único sócio à dissolução da sociedade, esta não deve ser decretada. Em razão do princípio da preservação da empresa, o sócio renitente tem o direito de conservar a sociedade, desde que se reembolsem as quotas dos demais e, no prazo de 180 dias, consiga-se atrair para o negócio pelo menos mais um interessado (evitando a dissolução por unipessoalidade).

Em se tratando de sociedade anônima, esse tipo de dissolução é discutido em assembleia geral extraordinária" ${ }^{11}$ (BRASIL, 1976), conforme

11 Art. 206. Dissolve-se a companhia: [...] c) por deliberação da assembleia-geral (art. 136, X) [...]. (BRASIL, 1976). 
estipula a legislação, sendo necessária a aprovação de acionistas que representem metade, no mínimo, das ações com direito a voto, se não for exigido quórum maior pelo estatuto social (art. 136, X, Lei n ${ }^{\circ} 6.404$, de 15 de dezembro de 1976 - Lei das S.A.).

A unipessoalidade é causa de dissolução quando a sociedade se reduz a apenas um sócio, ou seja, todas as cotas representativas do capital social de sociedade contratual forem reunidas sob a titularidade de uma só pessoa, física ou jurídica.

Conforme dispõe o art. 1.033, IV, do CC, é assegurado um prazo de 180 (cento e oitenta) para que seja reconstruída a pluralidade dos sócios. Decorrido este prazo, sem a admissão de novos sócios, a sociedade se dissolve e entra em liquidação. Neste sentido, Fabio Ulhôa Coelho (2012a, p. 352) esclarece que, na sociedade limitada a pluralidade dos sócios deve ser restaurada no prazo de 180 (cento e oitenta) dias após o evento da unipessoalidade, independente de reunião ou assembleia.

Caso não se encontre pessoa para associar-se, o sócio remanescente pode promover a transformação do registro da sociedade para empresário individual, ou EIRELI (Empresa Individual de Responsabilidade Limitada).

Ainda, caso não ocorra liquidação e atos de encerramento da sociedade pelo único sócio, e esta permaneça operando, será configurada sociedade irregular com a responsabilidade ilimitada do sócio. Corrobora com este entendimento, Fábio Ulhôa Coelho (2012a, p. 352):

Na sociedade limitada, a pluralidade de sócios deve ser restabelecida no prazo de 180 dias seguintes ao evento que produziu a unipessoalidade (isto é, a concentração de todas as quotas sob a titularidade de uma só pessoa física ou jurídica), independentemente 
das assembleias ou reuniões dos sócios (CC, art. 1.033, IV). Nesse mesmo prazo, se não encontrar ninguém com quem deseja se associar, para restabelecer a pluripessoalidade, o sócio remanescente pode evitar a dissolução procedendo à transformação do registro da sociedade em registro de empresário individual, ou de EIRELI (art. 1.033, parágrafo único). Vencido o lapso legal de sobrevivência sem a adoção dessas providências (a admissão de pelo menos mais um sócio, ou, sendo limitada a sociedade que se tornou unipessoal, pela transformação do seu registro), dissolve-se a sociedade empresária. Por outro lado, se o sócio único deixa de promover a liquidação e os atos de encerramento da pessoa jurídica, e continua esta operando, configura-se a situação de sociedade irregular. Ele passa, então, a ter responsabilidade ilimitada pelas obrigações sociais.

Com relação à Sociedade Anônima o artigo 206, I, d prevê que se dissolve a companhia "pela existência de 1 (um) único acionista, verificada em assembleia-geral ordinária, se o mínimo de 2 (dois) não for reconstituído até à do ano seguinte", exceto na hipótese de se tratar de sociedade subsidiária integral que tem como único acionista a sociedade brasileira (art. 251).

Por conseguinte, a extinção da autorização pode causar a dissolução total de pleno direito, especialmente para as sociedades sujeitas a autorização do governo, por exemplo bancos e seguradoras (art. 206, I, e, Lei das S.A., e art. 1.033, V, Código Civil).

Em continuidade, as hipóteses de dissolução total judicial, ou seja, com necessidade de decretação judicial, estão previstas no art. 1.034 do $\mathrm{CC}$ que engloba as seguintes causas, mediante requerimento de qualquer dos sócios: (i) anulação da constituição; e (ii) exaurimento 
ou inexequibilidade do fim social.

Frise-se que além das causas apresentadas nos artigos 1.034 e 1.033 do Código Civil, a sociedade pode ser dissolvida por outras causas previstas no contrato social, causas específicas, que venham a se relacionar com especialidades dos negócios ou até mesmo com a vontade dos sócios (art. 1.035 do Código Civil).

A anulação da constituição da sociedade é resultado dos casos de nulidade relativa ou nulidade de pleno direito da constituição da sociedade que podem gerar sua dissolução total.

Segundo Gladston Mamede (2015, p. 88), “a sentença que defere a anulação ou que declara a nulidade terá efeito de ato jurídico de dissolução, sendo que sua execução será liquidação da sociedade, concluindo-se como a extinção de sua personalidade jurídica”.

Outrossim, o exaurimento ou inexequibilidade do fim social ocorre quando a sociedade não mais completar seu fim social ou estiver praticando atividades em desacordo com a legislação pertinente, poderá ser dissolvida judicialmente.

Segundo Fábio Ulhôa Coelho o exaurimento do fim social é quando a "a sociedade é contratada exclusivamente para realizar uma determinada obra, operação ou serviço. Uma vez atendido o seu objetivo determinado, não há mais razão para continuar a pessoa jurídica" (2012b, p. 804). Por outro lado, de acordo com o referido autor, a inexequibilidade do objeto social tem por exemplos a inexistência de mercado para o produto ou serviço fornecido pela sociedade, ou seja, a falta de interesse dos consumidores; a insuficiência do capital social para produzir ou circular o bem ou serviço referido como objeto no contrato social; e a grave desinteligência entre sócios que impossibilite a continuidade de negócios comuns (COELHO, 2012b, p. 804-805). 
Gladston Mamede (2015, p. 88) informa que a sociedade se dissolve por iniciativa dos sócios ou através de ação civil pública quando o objeto social se tornar ilícito diante da lei posterior ou quando a lei determinar a dissolução de determinadas sociedades.

Diante da legislação das sociedades anônimas, a causa de dissolução pela inexequibilidade do objeto social é classificada como judicial, sendo que, é legitimo para o pedido o acionista titular, com no mínimo 5\% (cinco por cento) do capital social (art. 206, II, b, Lei das S.A).

Por fim, a falência também é uma causa de dissolução total judicial, na forma dos arts. 1.044, 1.046, 1.087 do Código Civil e 206, II, c da Lei das S.A. O tema não foi incluído no art. 1.033 do Código Civil, uma vez que este último está inserido no capítulo de Sociedade Simples Pura, de natureza não empresária, e, portanto, não sujeita à falência, diferentemente da Sociedade em nome coletivo (Art. 1.044), em comandita simples (Art. 1.046) e limitada (Art. 1.087).

\section{OS PROCEDIMENTOS DE DISSOLUÇÃO DE SOCIEDADES, À LUZ DO CÓDIGO DE PROCESSO CIVIL DE 1973}

As hipóteses de dissolução, total de pleno direito ou parcial, não dependem de provimento jurisdicional. Isto pois, as hipóteses de dissolução total de pleno direito admitem liquidação administrativa extrajudicial.

Apenas, quando não se operar consenso entre os sócios, a liquidação será promovida em juízo. Entretanto, a liquidação em juízo sempre se efetivará nas hipóteses de dissolução total judicial.

$\mathrm{O}$ art. 1.111 do Código Civil determina in verbis que "no caso de liquidação judicial, será observado o disposto na lei processual", 
remetendo a liquidação ao Código de Processo Civil de 1973.

Por sua vez, o Código de Processo Civil de 1973 determinou no art. 1.218 (BRASIL, 1973) ${ }^{12}$ que continuariam em vigor até serem incorporados nas leis especiais os procedimentos regulados pelo DecretoLei ${ }^{\circ} 1.608$ de 18 de setembro de 1939, em especial a dissolução e liquidação das sociedades, cujos procedimentos estavam previstos nos arts. 655 a 674 do Código de Processo Civil de 1939. Com tal entendimento, corrobora Alexandre Freitas Câmara (CÂMARA, 2014, p. 579):

Rege-se pelos arts. 655 a 674 do CPC/1939 o procedimento especial da dissolução e liquidação das sociedades.

[...] A extinção do ente chamado sociedade, dotado de personalidade jurídica própria, chama-se - na forma dos arts. 1.033 e seguintes do Código Civil dissolução. Como já se disse em boa doutrina, com a dissolução encerra-se a fase ativa da sociedade, que, a partir daí, entra em liquidação, que é uma espécie de preparação para a morte. Há alguns casos, previstos no art. 1.033 e seguintes do Código Civil, em que a sociedade se dissolve de pleno direito, isto é independentemente de pronunciamento judicial. Nas hipóteses previstas no art. 1.034 do Código Civil, porém, a dissolução da sociedade é judicial, só ocorrendo com o trânsito em julgado da sentença que se profere no procedimento especial[...].

$\mathrm{Na}$ forma do art. 1.111 do CC combinado c/ 1.218, VII do CPC/73, o Código de Processo Civil de 1939 regulamentou o

12 Art. 1.218. Continuam em vigor até serem incorporados nas leis especiais os procedimentos regulados pelo Decreto-lei no 1.608 , de 18 de setembro de 1939, concernentes: [...] Vll - à dissolução e liquidação das sociedades (arts. 655 a 674); [...]. (BRASIL, 1973). 
procedimento especial da dissolução total e liquidação. Neste sentido, o procedimento especial da dissolução total judicial até a entrada em vigor do Código de Processo Civil de 2015, estabelecia que o requerimento poderia ser feito por qualquer interessado.

A contestação era apresentada em 48 horas quando tratava-se de causa de dissolução de pleno direito, ou 5 (cinco) dias quando depende de provimento jurisdicional.

O juiz declararia a dissolvida a sociedade (quando a dissolução fosse de pleno direito na forma do art. 655), ou decretará a dissolução (quando contenciosa e dependente de decisão judicial), e desde logo nomearia o liquidante.

Nomeado o liquidante, este assinaria em 48 (quarenta e oito) horas o termo, e não o fazendo, o juiz nomearia o segundo imediato em votos, ou terceiro estranho, se por ele também recusada a nomeação.

Não dispondo o Contrato Social sobre quem deveria ser o liquidante, seria designada assembleia judicial de sócios, nos termos do art. 1.112 do Código Civil, aprovando-se por maioria absoluta na forma do art. $657 \S 1^{\circ}$ do CPC/39, salvo em Sociedade Limitada e Anônima, quando a aprovação se daria por maioria simples nos termos do art. 1.071, VII e 1.076, III do CC e art. 129 da Lei das S/A. Em caso de empate caberia ao juiz nomear terceiro estranho para o cargo (art. $657 \S 2^{\circ}, \mathrm{CPC} / 39$ ).

No curso do processo, enquanto não fosse nomeado o liquidante, seria possível o sequestro de bens (art. $659 \mathrm{CPC} / 39$ ) quando houvesse receio fundado de rixa, crime, extravio ou danificação de bens sociais. Tal medida se molda ao procedimento cautelar do art. $273 \S 7^{\circ}$ do $\mathrm{CPC} / 73$, e ao sequestro do art. 822 do $\mathrm{CPC} / 73$.

O procedimento do $\mathrm{CPC} / 39$, por força do art. 1.218, VII do $\mathrm{CPC} / 73$, somente não se aplicaria às hipóteses de dissolução total 
de sociedade não personificada (Arts. 673 CPC/73 e 986 do CC) e de sociedade anônima (art. $674 \mathrm{CPC} / 39$ ), cuja dissolução desafia o procedimento ordinário. Quanto à anônima, não contestado o pedido, a liquidação observará o disposto no procedimento especial do CPC/39.

Ultrapassada a análise dos procedimentos do Código de Processo Civil de 1973 para a dissolução total, passa-se a análise dos respectivos procedimentos para a dissolução parcial.

Quando a resolução da sociedade em relação a um sócio (dissolução parcial) se opera de pleno direito, a apuração de haveres poderá ser feita administrativamente, por via extrajudicial. Na hipótese de não haver consenso na apuração de haveres será judicial.

A Súmula 265 do Supremo Tribunal Federal determina que "na apuração de haveres, não prevalece o balanço não aprovado pelo sócio falecido ou que se retirou". Por outro lado, na hipótese de dissolução parcial judicial da sociedade, tanto a apuração de haveres, quanto a liquidação é judicial.

No Códigos de Processo Civil de 1973, e no Código de Processo Civil de 1939 não havia previsão acerca do procedimento da dissolução parcial. O art. 668 do CPC/39 dispôs que se a morte ou retirada do sócio não causarem a dissolução total, serão apurados exclusivamente os haveres do sócio falecido ou retirante.

Naquele tempo havia uma discussão se a norma contida no art. 668 do CPC/39 seria material ou heterotópica (material e processual). No caso de norma material, a apuração de haveres observaria o procedimento ordinário. No caso de norma heterotópica seria observado o procedimento especial de dissolução total do CPC/39.

De acordo com o entendimento jurisprudencial do Superior 
Tribunal de Justiça, pacificado no julgamento do RESP 1.139.593/SC ${ }^{13}$, sob relatoria da Ministra Nancy Andrighi, o procedimento a ser seguido é o rito ordinário, diante da inexistência à época de regras objetivas sobre a dissolução parcial de sociedades.

DIREITO PROCESSUAL CIVIL. RECURSO ESPECIAL.AÇÃODEAPURAÇÃO DEHAVERES. NEGATIVA DE PRESTAÇÃO JURISDICIONAL. NÃO OCORRÊNCIA. AUSÊNCIA DE PEDIDO E IMPOSSIBILIDADE DE SUA DEDUÇÃO A PARTIR DA CAUSA DE PEDIR. JULGAMENTO EXTRA PETITA. OCORRÊNCIA. PRESCRIÇÃO. PRAZO DECENAL. INOCORRÊNCIA. RITO PROCESSUAL. AUSÊNCIA DE REGRAMENTO ESPECIAL. PROCEDIMENTO ORDINÁRIO. AUSÊNCIA DE PREJUÍZO CONCRETO. NULIDADE AFASTADA.

1. Ação de apuração de haveres ajuizada em 21/7/2005. Recurso especial concluso ao Gabinete em 3/9/2009. 2. Demanda em que se discute a existência de violação de julgamento extra petita decorrente da declaração de dissolução parcial de sociedade em ação de apuração de haveres, bem como prazo prescricional e o rito procedimental aplicáveis à ação. 3. Ausentes os vícios do art. 535 do CPC, rejeitam-se os embargos de declaração. 4. A ausência de pedido expresso, bem como de causa de pedir que permita deduzi-lo, impede a declaração da dissolução parcial da empresa, situação de fato já consolidada, por ofender o princípio da adstrição e importar em julgamento extra petita. 5. Aplica-se às ações de apuração de haveres o prazo prescricional decenal, por ausência de regra específica. 6. A apuração de haveres decorrente de dissolução parcial não é regulada especificamente por lei, porquanto 
a própria dissolução parcial representa criação doutrinária e jurisprudencial, aos poucos incorporada no direito posto. 7. Diante da inexistência de regras objetivas, aplica-se o procedimento ordinário à ação de apuração de haveres - ação de natureza eminentemente condenatória. 8. Apesar da aplicação de rito especial de forma indevida, deve-se analisar a nulidade a partir das lentes da economia processual, efetividade, respeito ao contraditório e ausência de prejuízo concreto. 9. Recurso especial parcialmente provido.

\section{O CÓDIGO DE PROCESSO CIVIL DE 2015 E AS ALTERAÇÕES PROPOSTAS PARA A DISSOLUÇÃO PARCIAL DAS SOCIEDADES.}

Em relação à dissolução total de sociedades à luz do Código de Processo Civil de 2015, importa notar que este, na forma de seu art. 1.046 revogou a Lei no 5.869 de 11 de janeiro de 1973 (Código de Processo Civil de 1973).

A partir de sua vigência tornam-se inaplicáveis os procedimentos especiais da Lei 5.869/1973 que incluem o procedimento especial de dissolução e liquidação de sociedades, em que serão aplicados o procedimento comum.

Não há no novo diploma processual quaisquer procedimentos especiais que regulamentem a dissolução total judicial de sociedades.

O art. 1.049 do Código de Processo Civil de 2015 determina que "sempre que a Lei remeter a procedimento específico previsto na Lei processual sem especificá-lo, será observado o procedimento comum previsto neste Código". Portanto, conforme o referido artigo, combinado com o art. 1.111 do Código Civil e art. 209, parágrafo único 
da Lei 6.404/1976, podemos concluir que a dissolução total quando judicializada, passa a observar o procedimento comum previsto nos arts. 318 a 512 do Código de Processo Civil de 2015, não mais se aplicando o procedimento especial do Código de Processo Civil de 1939, conforme afirma Pablo Gonçalves (GONÇALVES, 2015):

Com a esperada vigência do novo CPC, fica expressamente revogada a Lei 5.869, de 11 de janeiro de 1973 (CPC/73).

[..] A partir de sua vigência, tornam-se inaplicáveis os procedimentos especiais do $\mathrm{CPC} / 39$ que até então mantinham sua vigência por força do Art. 1.218 do $\mathrm{CPC} / 73$, o que inclui o procedimento especial de dissolução e liquidação de sociedades, para o que, salvo expressa previsão do novo Código, será aplicado o procedimento comum, como determina o parágrafo terceiro do Art. 1.046, CPC/15.

Dessa forma, a dissolução total de sociedade, quando judicializada, passará a observar o procedimento comum previsto na Lei. $13.105 / 15$, não mais se aplicando o procedimento especial previsto no CPC/39 (art. 1.218, VII, CPC/73). Soma-se, ainda, o fato de que o Art. 1.049 da referida Lei afirma que "sempre que a lei remeter a procedimento previsto na lei processual sem específicá-lo, será observado o procedimento comum previsto neste Código", e os Art. 1.111 do Código Civil e 209, parágrafo único, da L. 6.404/76 fazem essa exata referência.

A dissolução parcial das sociedades passa a ter procedimento especial no Código de Processo Civil de 2015, no capítulo V, denominado da ação de dissolução parcial de sociedade. O referido diploma apresenta justamente a expressão "Ação de dissolução parcial", conflitando com 
o Código Civil de 2002 que versa sobre a "resolução da sociedade em relação a um sócio". Desta forma, com a regulamentação da ação de dissolução parcial, como procedimento especial do novo código de processo civil, os questionamentos doutrinários acerca da invalidade da espécie dissolução parcial de sociedades tiveram um amparo legal, porém não deixaram de ser questionados. Entretanto, a dissolução parcial é uma realidade, e seu procedimento deve ser seguido.

Deve ser ressaltado que sob atual e pertinente perspectivas de Alexandre Ferreira de Assumpção Alves e Allan Turano (2016, p. 90) a escolha desta denominação não foi adequada, uma vez que o Código Civil já se manifestou materialmente sobre tal questão, tratando da resolução da sociedade em relação a um sócio:

Ação de dissolução parcial é o nomen iuris do procedimento adequado para a tutela judicial da resolução da sociedade em relação ao sócio, atribuído pelo CPC/2015.

A escolha dessa denominação pelo legislador não foi a mais apropriada. Inicialmente, já se discutiu sobre a atecnia da expressão dissolução parcial. Adicionalmente, desde a edição do Código Civil de 2002 não há que se utilizar do termo, uma vez que a matéria é hoje regulada, no plano material, pelo instituto da resolução sociedade em relação ao sócio.

$\mathrm{O}$ art. $599^{14}$ do referido instrumento (BRASIL, 2015) delimita o objeto da ação à resolução da sociedade em relação um sócio e/ou apuração de haveres. Nos casos em que a dissolução parcial se opera

14 Art. 599. A ação de dissolução parcial de sociedade pode ter por objeto: I - a resolução da sociedade empresária contratual ou simples em relação ao sócio falecido, excluído ou que exerceu o direito de retirada ou recesso; e II - a apuração dos haveres do sócio falecido, excluído ou que exerceu o direito de retirada ou recesso; ou III - somente a resolução ou a apuração de haveres. [...] (BRASIL, 2015). 
independentemente de provimento judicial, a demanda versará apenas sobre a apuração de haveres, nas hipóteses de resolução que dependa de ação, será de dissolução e apuração de haveres.

Alexandre Ferreira de Assumpção Alves e Allan Turano (2016, p. 93) elucida que "a natureza da ação é distinta em cada hipótese, podendo ser declaratória, desconstitutiva, declaratória-condenatória ou desconstitutiva-condenatória. A natureza da ação, portanto, está diretamente ligada ao direito material".

Sob esta ótica, por exemplo, no caso de sócio que tenha exercido seu direito de retirada, e ingresse com a ação de dissolução parcial, com intuito apenas de resolução em relação a si, o procedimento terá natureza declaratória. Todavia, caso o autor tenha formulado também pedido de apuração de haveres, o procedimento terá natureza declaratóriacondenatória. Conforme afirmam os referidos autores (ALVES; TURANO, 2016, p. 94), a ação apenas de apuração de haveres também possui esta natureza porque " é pressuposto para que o juízo condene a sociedade a efetuar o reembolso, a declaração do direito do sócio ao recebimento do valor de sua participação societária”.

A ação possuirá natureza desconstitutiva, no caso de exclusão do sócio por atos de inegável gravidade, quando os efeitos serão produzidos a partir do trânsito em julgado. Considerando que o sócio excluído é o verdadeiro interessado da apuração de haveres, não há necessidade do autor da ação solicitar este pedido. O juiz não poderá de ofício determinar a condenação, pois os sócios podem acordar sobre o reembolso, podendo fazê-lo extrajudicialmente. Contudo, no caso de divergência entre os sócios, o autor pode formular cumulativamente os pedidos, ou ainda, o réu poderá em contestação apresentar pedido contraposto, requerendo subsidiariamente a apuração de haveres, tratando-se tais hipóteses de 
ações com natureza desconstitutiva-condenatória.

Importa notar que o art. 599, I, limita a ação de dissolução parcial apenas à sociedade contratual. Contudo o parágrafo segundo do art. 599 (BRASIL, 2015) admite a ação de dissolução parcial para a sociedade anônima de capital fechado quando solicitado por acionista(s) que representem $5 \%$ ou mais do capital social, que não pode preencher seu fim.

Como visto anteriormente, a Lei no 6.404 de 1976 prevê no art. 206, II, b que quando a sociedade anônima não atinge seu fim, uma minoria ativa formada por acionistas que representem ao menos 5\% (cinco por cento) do capital social pode propor a dissolução total judicial da sociedade e não a dissolução parcial.

Neste sentido, o Código de Processo Civil representa um avanço no direito societário, na medida em que tal disposição é compatível com os princípios de preservação e função social da empresa.

O prazo para apresentação da contestação, estabelecido no procedimento especial, é de 15 dias, do sócio e sociedade. Todavia, a sociedade não será citada se todos os sócios o forem (Art. 601 e parágrafo único do art. 601 do CPC de 2015).

Além disso, o diploma prevê que é cabível pedido de indenização pela sociedade, compensável com valores dos haveres a apurar (art. 602 do $\mathrm{CPC} / 2015)$.

Havendo concordância das partes com a dissolução o juiz a decretará, passando-se à fase de apuração de haveres. Porém, havendo contestação, observar-se-à o procedimento comum na ação de dissolução parcial, na forma do art. 603, $\S 2^{\circ}$ do CPC de 2015.

O procedimento de apuração de haveres na dissolução parcial está previsto no art. 604 e seguintes do CPC de 2015. 
O juiz fixará a data de resolução da sociedade, que poderá ser: (i) a data do óbito, no caso de falecimento do sócio; (ii) em caso de retirada imotivada, o $60^{\circ}$ (sexagésimo) dia seguinte ao recebimento pela sociedade da notificação do sócio dissidente; (iii) na hipótese de recesso, o dia de recebimento pela sociedade da notificação do sócio dissidente; (iv) nas causas de dissolução judicial, o trânsito em julgado da decisão que a dissolver; e (v) na exclusão extrajudicial, a data da assembleia ou reunião dos sócios que a deliberou.

Por conseguinte, o juiz definirá o critério de apuração de haveres, nomeará o perito e determinará à sociedade ou aos sócios que nela permanecerem que depositem em juízo a parte incontroversa dos haveres devidos, podendo o ex-sócio, espólio ou sucessores desde logo, levantarem o depósito.

Na hipótese de o contrato social estabelecer o pagamento dos haveres, será observado o que nele se dispôs no depósito judicial da parte incontroversa. Entretanto, em caso de omissão do contrato social o juiz definirá como critério de apuração de haveres, o valor patrimonial apurado em balanço de determinação, tomando-se por referência a data da resolução e avaliando-se bens e direitos do ativo, tangíveis e intangíveis, a preço de saída, além do passivo a ser apurado de igual forma.

A data de resolução e o critério de apuração de haveres podem ser revistos pelo juiz, a pedido da parte, a qualquer tempo antes do início da perícia.

Importante notar que o valor da liquidação não poderá ser o valor das quotas disposto no contrato social, ou nos últimos balanços, mas no verdadeiro valor da participação societária, avaliado mediante balanço específico para tanto, conforme assevera Gladston Mamede (2015, p. 88): 
Com a retirada do sócio, em qualquer das hipóteses acima listadas, faz-se necessário liquidar sua quota ou quotas da sociedade. Essa liquidação não se faz pelo reembolso do valor das quotas segundo o contrato social, nem com base no último balanço social, mas como base na situação patrimonial da sociedade, à data da resolução, verificada em balanço especialmente levantado, salvo disposição contratual em contrário (art. 1.301 do Código Civil), desde que legitimamente estatuída; com efeito, é essencial que não haja abusos e que o pagamento se faça pelo valor real da participação societária.

Uma vez apurados os haveres ao sócio retirante serão pagos na forma do contrato social ou, no silencio, na forma do $\S 2^{\circ}$ do art. 1.031 do Código Civil, que determina que a quota liquidada será paga em dinheiro no prazo de 90 (noventa) dias a partir da liquidação.

\section{CONCLUSÃO}

Podemos dividir as causas de dissolução, de acordo com o Código Civil, pelas suas consequências, sendo certo que a dissolução parcial pressupõe a manutenção da sociedade e de sua personalidade jurídica, com a saída de um ou mais sócios e a respectiva liquidação de suas quotas, e a dissolução total por sua vez levará à extinção completa da sociedade, e sua personalidade jurídica.

O Código de Processo Civil de 1973 (Lei 5.869, de 11 de janeiro de 1973) determinou que continuariam em vigor até serem incorporados nas leis especiais os procedimentos regulados pelo Decreto-lei $n^{0}$ 1.608, de 18 de setembro de 1939 (Código de Processo Civil de 1939), concernentes a dissolução e liquidação das sociedades (art. 1.218, VII 
do $\mathrm{CPC} / 73)$.

Deste modo, o Código de Processo Civil de 1939 regulamentou, até a entrada em vigor do Código de Processo Civil de 2015, o procedimento especial de dissolução de sociedades.

Importa notar que o referido diploma apenas disciplinou a dissolução total de sociedades, e respectiva liquidação, ambos como procedimentos especiais.

O novo Código de Processo Civil (Lei n ${ }^{\circ} 13.105$, de 16 de março de 2015) que passou a vigorar a partir de 16 de março de 2016, positivou a Ação de Dissolução Parcial de Sociedades como procedimento especial, e, revogou a Lei 5.869 de 1973, assim como todos os procedimentos especiais previstos no Decreto-lei n ${ }^{\circ} 1.608$, de 18 de setembro de 1939.

Neste sentido, as divergências doutrinárias acerca da dissolução parcial que antes era tratada expressamente como resolução da sociedade em relação a um dos sócios, na forma do Código Civil de 2002, permanecem, em razão da atecnia da nomenclatura.

Pelo exposto, a dissolução parcial de sociedades, e liquidação da quota do sócio falecido, retirado ou excluído, passam a ser reguladas pelo procedimento especial específico do Código de Processo Civil de 2015, enquanto a dissolução total de sociedades deverá seguir o procedimento comum do novo código.

\section{REFERÊNCIAS}

ALVES, Alexandre Ferreira de Assumpção; TURANO, Allan Nascimento. A resolução da sociedade em relação a um sócio e a ação de dissolução parcial. Curitiba: Juruá, 2016.

BRASIL. Lei $\mathbf{n}^{\mathbf{0}} \mathbf{1 0 . 4 0 6}$, de 10 de janeiro de 2002. Institui o Código 
Civil. Disponível em: $<$ http://www.planalto.gov.br/ccivil_03/leis/2002/ L10406.htm>. Acesso em: 29 mar. 2017.

BRASIL. Lei $\mathbf{n}^{\mathbf{0}} \mathbf{1 3 . 1 0 5}$, de 16 de março de 2015. Código de Processo Civil. Disponível em: <http://www.planalto.gov.br/ccivil_03/_ato20152018/2015/lei/113105.htm>. Acesso em: 7 out. 2016.

BRASIL. Lei $\mathbf{n}^{\mathbf{0}}$ 3.071, de $\mathbf{1}^{\mathbf{0}}$ de janeiro de 1916. Código Civil dos Estados Unidos do Brasil. Disponível em: $<$ http://www.planalto.gov.br/ ccivil_03/leis/L3071.htm>. Acesso em: 7 out. 2016.

BRASIL. Lei $\mathbf{n}^{0}$ 5.869, de 11 de janeiro de 1973. Institui o Código de Processo Civil. Disponível em: <http://www.planalto.gov.br/ccivil_03/ leis/L5869.htm>. Acesso em: 29 mar. 2017.

BRASIL. Lei $\mathbf{n}^{0}$ 6.404, de 15 dezembro de 1976. Dispõe sobre as Sociedades por Ações.

Disponível em: <http://www.planalto.gov.br/ccivil_03/leis/L6404consol. htm>. Acesso em: 29 mar. 2017.

BRASIL. Tribunal de Justiça do Estado do Rio de Janeiro. $20^{\text {a }}$ Câmara Cível. Apelação cível no 0143943-58.2009.8.19.0001. Des. Rel. Myriam Medeiros da Fonseca Costa. J: 13/06/2012. DJ:25/06/2012.

BRASIL. Superior Tribunal de Justiça. $3^{\text {a }}$ Turma. Recurso Especial $\mathbf{n}^{\mathbf{}}$ 1.139.593/SC. Min. Rel. Nancy Andrighi. J: 22/04/2014. DJ: 2 maio 2014.

CÂMARA, Alexandre Freitas. Lições de direito processual civil. 21. ed. São Paulo: Atlas, 2014. v. 3.

CAMPINHO, Sérgio. O direito de empresa a luz do Código Civil. 13. ed. Rio de Janeiro: Renovar, 2014. 
COELHO, Fábio Ulhôa. Curso de Direito Comercial: direito de empresa. 16. ed. São Paulo. Saraiva. 2012a. v.2

. Manual de direito comercial. 24. ed. São Paulo: Saraiva, 2012b.

ESTRELLA Hernani. Despedida do sócio e apuração dos haveres. Porto Alegre: José Konfino Editor, 1948.

GONÇALVES, Pablo. Dissoluções de Sociedade e o Novo CPC. Revista da Emerj, Rio de Janeiro, v. 18, n. 70, 2015. Disponível em: <http://www. emerj.tjrj.jus.br/ revistaemerj_online/edicoes/revista70/revista70_168. pdf $>$. Acesso em: 7 jun. 2016.

MAMEDE, Gladston. Manual de Direito Empresarial. 10. ed. São Paulo: Atlas, 2015.

REQUIÃO, Rubens Edmundo. Curso de direito comercial. 29. ed. São Paulo: Saraiva, 2012. v. 2.

Como citar: LISBOA, Letícia Lobato Anicet, SANT'ANNA, Leonardo da Silva. Dissolução das sociedades à luz das alterações previstas no Código de Processo Civil de 2015. Scientia Iuris, Londrina, v. 21, n. 3 , p.158-188, nov. 2017. DOI: $10.5433 / 2178-8189.2017 \mathrm{v} 21 \mathrm{n} 3$ p158. ISSN: 2178-8189.

Recebido em 30/03/2017

Aceito em 05/09/2017 